\title{
Tipología textual y problemas matemáticos para fortalecer la comprensión lectora
}

\section{Textual typology and mathematical problems as a means to enhance reading comprehension}

\author{
Carlos Alex Granados Villarraga \\ Especialista en Gestión de Proyectos Informáticos \\ Secretaría de Educación, Gobernación de Norte de Santander, \\ Cúcuta, Colombia \\ Correo electrónico: cgranados188@unab.edu.co \\ Eulalia Peñaranda Vargas \\ Especialista en Gerencia de la Informática Educativa \\ Instituto Superior de la Educación Rural (ISER), Pamplona, Norte de Santander, Colombia \\ Correo electrónico: euly2006@yahoo.es
}

Recibido: 26 de julio de 2017. Aprobado: 15 de septiembre de 2017

\section{Cómo citar este artículo:}

Granados, C. A., y Peñaranda, E. (2018). Tipología textual y problemas matemáticos para fortalecer la comprensión lectora. Espiral, Revista de Docencia e Investigación, 8(1), 81 - 101.

\section{Resumen}

Objetivo. El presente artículo es el resultado de una investigación cuyo objetivo es fortalecer la comprensión lectora mediante la implementación de una estrategia pedagógica desde las áreas de lenguaje en tercero de primaria y de matemáticas en sexto grado de la institución educativa Colegio Integrado Fe y Alegría del municipio de Los Patios, Norte de Santander.

Metodología. El estudio propone acciones y estrategias pedagógicas de acuerdo con los resultados de las Pruebas Saber, en las que se evidenció que era necesario fortalecer los procesos de lectura en los estudiantes, motivándoles para crear hábitos, mediante la propuesta de intervención pedagógica "Tipología textual y resolución de problemas matemáticos", con el fin de potenciar la comprensión lectora y mejorar los resultados de las Pruebas Saber y desempeños en las diferentes áreas del conocimiento.

Resultados. El diseño metodológico utilizado durante el proceso fue la investigación acción con enfoque cualitativo, empleando los siguientes instrumentos para la recolección de la información: prueba diagnóstica, diario pedagógico y las rejillas de evaluación. Durante la aplicación de la intervención fue necesario la implementación de varios talleres pedagógicos, logrando finalmente una efectividad de la estrategia para fortalecer la comprensión lectora en un $75 \%$, resultados alcanzados en los desempeños de los estudiantes, durante el primer período académico del 2018.
Palabras clave: Comprensión lectora, estrategia pedagógica, investigación, problemas matemáticos, tipología textual.

\section{Abstract}

Objetive. This research was carried out at the Autonomous University of Bucaramanga, to obtain the title of Master in Education, aimed at strengthening reading comprehension through the implementation of a pedagogical strategy from the areas of language in third grade of primary and mathematics in sixth degree of the Educational Institution Fe y Alegria Integrated College of the Municipality of Los Patios Norte de Santander.

Methodology. The study proposes pedagogical actions and strategies according to the results of the Sagber Tests, where it was evidenced that it is necessary to strengthen the reading processes in the students, motivating them to create reading habits through the Pedagogic intervention proposal "Textual Typology and resolution of Mathematical problems ", in order to strengthen reading comprehension and obtain better results from the Knowledge Tests and performances in the different areas of knowledge.

Results. The methodological design used during the process was action research with qualitative method, using the following instruments for the collection of information: diagnostic test, pedagogical diary and evaluation grids; During the implementation of the strategy it 
was necessary to implement several pedagogical workshops, finally achieving an effectiveness of the strategy to strengthen the reading comprehension, in $75 \%$, results achieved in the performances of the students, during the first period of 2018.

Keywords: Reading comprehension, pedagogical strategy, research, mathematical problems, textual typology.

\section{Introducción}

El artículo está sustentado en el desarrollo de la investigación-acción "Estrategia pedagógica para fortalecer la comprensión lectora desde el área de lenguaje en grado tercero y matemáticas en grado sexto de la institución educativa Colegio Integrado Fe y Alegría del municipio de Los Patios, Norte de Santander". Los docentes, en su rol de investigadores, se preocupan, pero a su vez les motiva mejorar los desempeños académicos de sus estudiantes, en las competencias comunicativas en lenguaje y matemáticas como lo evidencian las Pruebas Saber de los años anteriores en los grados $3^{\circ}$ y $5^{\circ}$. Por esto, el propósito del estudio es el fortalecimiento de la comprensión lectora en estas áreas y proponen el taller como estrategia pedagógica mediadora para lograrlo, luego de una fase diagnóstica en la que identificaron los niveles de lectura en que se hallaron: tan solo hasta el literal.

La intervención pedagógica fue aplicada a un grupo con quienes realizan sus prácticas y de la observación del desarrollo de los talleres, una vez sistematizada y analizada la información es compartida por los docentes con la comunidad educativa.

\section{Tipo de investigación}

El estudio se centra en una investigaciónacción, con enfoque cualitativo, en razón a que presenta las características fundamentales para enfrentar los fenómenos de carácter social, en específico el campo de la educación, permitiendo la reflexión y la transformación de las prácticas pedagógicas. El docente tiene la oportunidad de hacer de su actividad profesional un escenario para conocer los diferentes problemas que se presentan en el aula, estudiando el contexto y haciendo una reflexión que pueda comprender la realidad a través de la reconstrucción de acciones, dinámicas, prácticas comunicativas y demás. Por consiguiente, el enfoque cualitativo que busca dar soluciones a una problemática a través de una estrategia pedagógica.

Para Elliot (2000) "en la investigación-acción el rol del profesor es desarrollar estrategias para llevar a la práctica esos principios en el aula" (p. 23). La acción investigativa cualitativa en el campo de la educación busca situarse en las relaciones cotidianas, ya sea entrando en los espacios comunicativos o reconstruyendo dinámicas interpersonales de las acciones, con esto se crean y recrean las realidades sociales; en nuestro caso como un conjunto de prácticas educativo-pedagógicas situadas (Badilla, 2006, p. 44).

El interés de este trabajo de investigación es mediante las practicas pedagógicas, observar situaciones educativas desde una perspectiva científica que intervienen en la construcción del conocimiento, puesto que es de gran relevancia que los estudiantes reivindicaran su rol como protagonistas en el proceso de enseñanza-aprendizaje de manera que, la comprensión de la realidad se puede estudiar o investigar a partir del mismo individuo según lo explican sus teorías del mundo, su sociedad y su entorno inmediato.

\section{Procesos de la investigación}

Inicialmente se hace un primer acercamiento al problema que se presenta con los estudiantes de tercer y sexto grado de la institución educativa Colegio Integrado Fe y Alegría del municipio de los Patios, Norte de Santander, al indagar sobre las situaciones a través de la ob- 


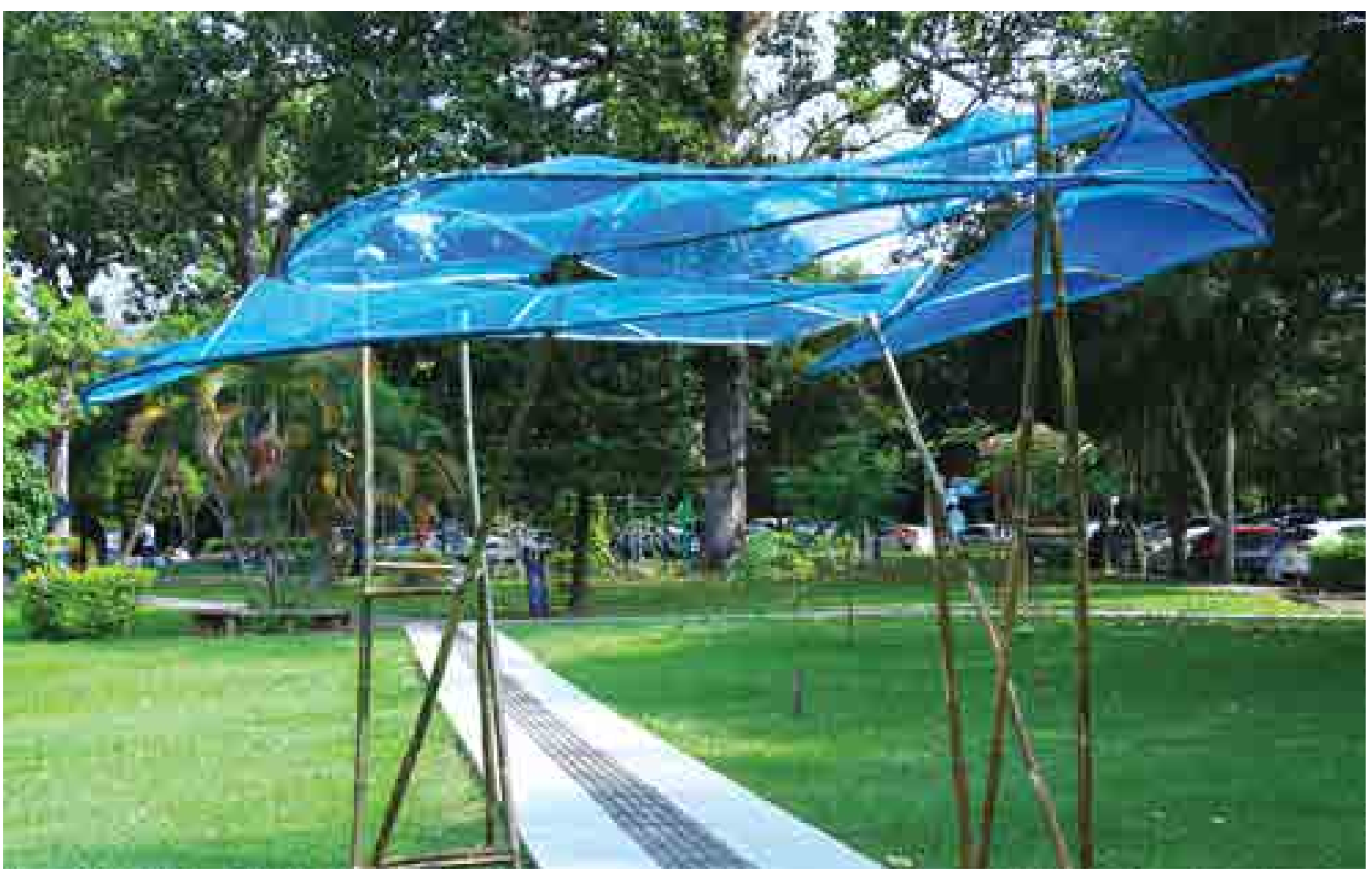

Proyecto Ecodumun.

servación de escenarios educativos desde una perspectiva científica en la que nos enfocamos en la construcción del conocimiento, se infiere la ausencia de comprensión lectora de los estudiantes. A partir de la observación del contexto, la investigación ubica el planteamiento del problema, el cual muestra resultados importantes a medida que se aplican las estrategias de recolección de la información para la comprensión de textos, en los niños de tercer grado. Esta circunstancia propició que se seleccionara el tipo de población con la cual se trabajaría. En esta fase cabe resaltar, el trabajo empírico con estudiantes, docentes y libros de texto que permitió elaborar las conclusiones iniciales de forma inductiva. Posteriormente, se establecería la relación directa con las categorías y la teoría de la lectura. Esta etapa consta de dos momentos. El primero hace referencia al momento reflexivo que esclarece y redefine el tema en cuestión. $Y$ un segundo momento, que abarca plantear los interrogantes que son la base que posibili- tan establecer las preguntas orientadoras. Es en este espacio donde se permite ubicar las problemáticas en niveles determinados de análisis para ser pensadas de forma concreta.

\section{Selección del tema y planteamiento del problema}

La selección del tema "comprensión lectora en los estudiantes de tercer grado y sexto de la institución educativa Colegio Integrado Fe y Alegría", fue un ejercicio que resultó del análisis de los resultados de las Pruebas Saber, al igual que los bajos desempeños académicos que los estudiantes presentan en las diferentes áreas del conocimiento. El interés por desarrollar una estrategia pedagógica para fortalecer la comprensión lectora desde el área de lenguaje en tercer grado y de matemáticas en sexto grado, fue el de proporcionarles a los niños en sus clases contenidos relacionados con las competencias en el lenguaje de forma dinámica, y como 
agentes investigadores al indagar no solo sobre las falencias que presentan los estudiantes en el momento de enfrentarse a un texto de tipo expositivo o informativo para su comprensión, sino además de lo evidente que resulta que el lenguaje es un campo que permea todas las áreas del conocimiento.

El planteamiento del problema se construyó con base en las observaciones de aula realizadas en los grados tercero y sexto. Se evidenció en esta instancia, la escasa comprensión de los textos trabajados en clase, las prácticas pedagógicas tradicionales y reduccionistas en relación con la enseñanza de la lectura. Además, se hizo una revisión de investigaciones existentes sobre lectura, específicamente la comprensión lectora en el nivel de primaria. Se halló poca literatura al respecto, sumado a la manera como se interactúa con el lenguaje a través de talleres para favorecer los aprendizajes significativos de los estudiantes.

\section{Proceso metodológico}

En una primera fase de la investigación se identificó el problema, que se planteó así: ¿Cómo fortalecer la comprensión lectora desde las áreas de matemáticas y lenguaje en los estudiantes de tercero de primaria y sexto de la institución educativa Colegio Integrado Fe y Alegría del municipio de Los Patios, Norte de Santander? Ello se hizo manifiesto en los bajos desempeños de los estudiantes, según los resultados del índice sintético de calidad educativa que en el factor progreso se redujo de 1.51 en el 2016 a 0.77 para el año siguiente, este factor nos indica que la institución no ha avanzado académicamente, además, los resultados de las Pruebas Saber 2016 para los grados tercero y quinto muestran las debilidades de los estudiantes en las competencias comunicativas en lenguaje y matemáticas.

De acuerdo con estos resultados los docentes investigadores ven la necesidad de implementar acciones que contribuyan con el fortalecimiento de la comprensión lectora, convirtiéndose esta intención en el objetivo general de la investigación. Una vez realizada la fundamentación de teóricos como Jolibert (1991), Solé (1987), Lerner (1986), López (2013), Márquez y Prat (2005) que sustentan este informe en cuanto a las estrategias que los docentes deben implementar para favorecer el proceso de comprensión lectora y Rico y Lupiáñez (2008) en los sistemas matemáticos, como también Polya (1965) que propone los cuatro pasos para resolver problemas matemáticos. Las actividades dentro de la estrategia pedagógica fundamentada en Solé (1987) hace referencia los tres momentos de la lectura, incluidos en la implementación de los talleres pedagógicos y también, siguiendo a Polya (1965), nos facilitó el diseño metodológico, las técnicas, métodos y herramientas que permitieron, recopilar la información que muestra resultados.

En una primera etapa diagnóstica se identificó el nivel de lectura de los estudiantes que con cierta dificultad alcanzaban el nivel literal. Luego se hizo la intervención pedagógica con los talleres curriculares que, durante el desarrollo registraron el desempeño de los estudiantes en las rejillas de evaluación con la observación principal direccionada con indicadores que evidenciaran los tres niveles de lectura (literal, inferencial y crítico). Con base en el registro del anterior documento, los docentes investigadores en sus diarios pedagógicos reflexionaban sobre las fortalezas y también las debilidades de las actividades, lo cual permitía replantear situaciones para mejorar la estrategia. Finalmente, se aplicó la prueba final para evaluar los resultados.

\section{Elaboración talleres}

La intervención pedagógica se hizo con una serie de talleres curriculares, con actividades acordes con el contexto inmediato de los estudiantes, de manera que fuese más fácil la estructuración de los procesos de enseñanza y aprendizaje, con el fin de evitar la improvisación y la dispersión de los contenidos, mediante un 
proceso reflexivo en el que participaran los estudiantes, el docente, los saberes de la asignatura y la sociedad como tal, con el fin de fortalecer la comprensión lectora en los estudiantes de tercero y sexto de la institución educativa.

\section{Resultados y discusión}

A continuación se presentan los hallazgos que se derivaron del trabajo investigativo, que se realizó con los estudiantes de tercero y sexto grado de la institución educativa Colegio Integrado Fe y Alegría del municipio de Los Patios, Norte de Santander, donde se llevaron a cabo observaciones mediante las intervenciones pedagógicas, con el propósito de analizar e interpretar el estado de la comprensión lectora para realizar acciones que contribuyan con el logro de los objetivos de este estudio.

Figura 1. Estudiante de tercer grado, taller de "Tipología textual" la línea de tiempo

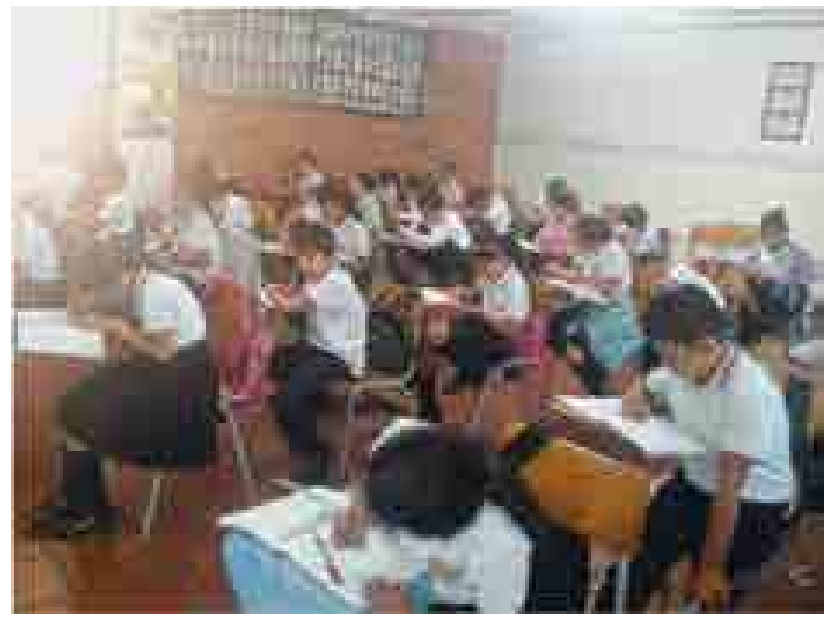

Durante la primera intervención pedagógica, cuyo objetivo principal fue observar el nivel de comprensión lectora a través de la línea de tiempo en los niños de tercer grado, la percepción de los estudiantes frente a los diferentes momentos de la misma y la motivación permitió llevar acabo la actividad con efectividad y agrado.

El desarrollo de la temática de las actividades permitió la discusión de los estudiantes frente al tema de la línea de tiempo como una forma de investigar y extraer información, para luego poderla plasmar en un esquema que permita fácilmente comprender la información del texto, además se observa la dificultad de interpretación por el número de veces que los estudiantes preguntan qué es lo que deben hacer.

El taller consta de tres momentos, durante la actividad de inicio, los educandos utilizan sus presaberes y los relacionan con los nuevos conocimientos, también se conceptualiza el tema donde se resalta la importancia de la línea de tiempo como un mecanismo de investigación, para conocer los momentos más importantes de un tema o un objeto, así mismo se dan las instrucciones para su elaboración, y se hace un primer ejemplo sobre la historia de la vida de la bicicleta.

Este momento fue de gran relevancia, porque se observó la motivación de los estudiantes en la lectura de la imagen, además pudieron realizar la línea de tiempo a través de la lectura que previamente se les entregó. La construcción se hizo con la ayuda de la docente, quien fue orientando el proceso.

Mediante el desarrollo de la actividad se disponen a organizar sus apuntes, se hacen varios ejemplos, investigan sobre la vida de Rafael Pombo y de la historia de los teléfonos en Colombia, se les entrega el material para que organicen la información en una línea de tiempo, para socializar a los compañeros y al profesor. Durante esta actividad se observa la dificultad que presentan los estudiantes para expresarse frente a sus demás compañeros, los apuntes fueron de muy buena calidad, aunque algunos presentan dificultades en el manejo de regla, omiten letras en sus escritos y se les dificulta extraer las fechas en orden cronológico, para organizarlas en la ficha, se encontraron muy buenos registros de los estudiantes, pero muchas dificultades en la comprensión lectora, ya que algunos presentaron copias de otros compañeros, dejando ver la apatía por la lectura y la escritura. 
En la fase de cierre se evalúa lo aprendido frente a la ampliación de conceptos con referencia al tema, la producción de textos se hizo a través de la elaboración e interpretación de las varias líneas de tiempo, ya que fue necesario la realización de varias sesiones, para lograr que los estudiantes se familiarizaran con la estrategia, esta actividad permitió a través de su producción textual determinar el nivel de comprensión lectora en los estudiantes de tercero, a pesar de que en el primer taller se observó que las diferentes actividades, como realizar investigaciones, completar información, indagar y, por último, la elaboración de su propia línea de tiempo, de una forma creativa, para luego exponerla frente a sus compañeros, es aquí donde se evidencia lo aprendido durante el taller y se podría decir que en un $90 \%$ generó cambios positivos en los estudiantes frente a la lectura.

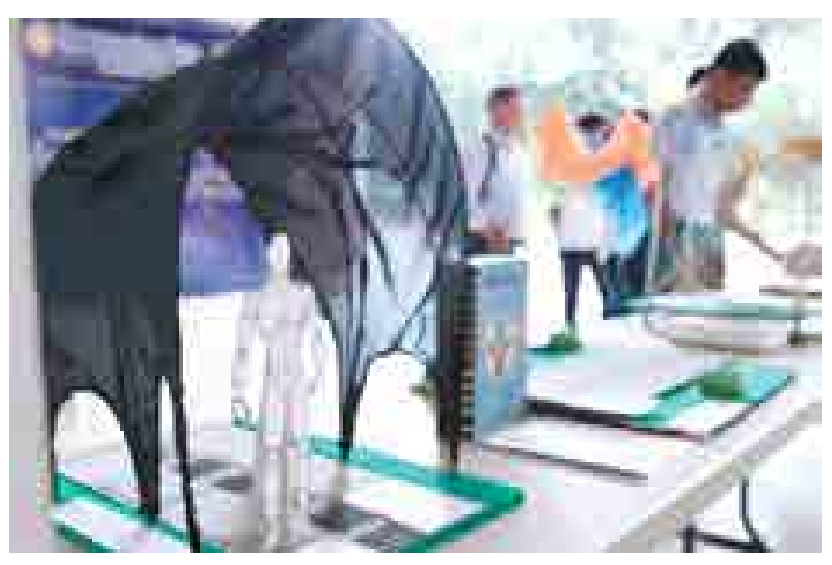

Durante la intervención 2, el taller pedagógico llamado "El diagrama de Venn, con estudiantes del grado 302 de la institución educativa Colegio Integrado Fe y Alegría del municipio de Los Patios. El cual fue ejecutado en los tres momentos contemplados en la guía, se da inicio con las orientaciones para el ejercicio de la actividad con el fin de fortalecer el trabajo en equipo, seguidamente se realizó una oración y las recomendaciones sobre normas y pautas de convivencia escolar, con el fin de hacer un trabajo agradable para todos, de igual manera se le entregó a cada niño una tableta, donde se encuentra el material para el desarrollo de la actividad.
En el momento de la conceptualización, los niños consignan en sus cuadernos de apuntes el material que les ayudará a ampliar la información sobre la identificación del diagrama de Venn, como un esquema que le permite al estudiante organizar una lista de elementos que cumplen con una misma característica, inmediatamente se les presenta el problema y la gráfica, los niños en su mayoría, lo relacionan con una actividad de matemáticas, que tiene que ver con los conjuntos, por lo cual la maestra investigadora los orienta sobre la importancia de los esquemas mentales, tanto en matemáticas, lenguaje y demás áreas del conocimientos para lograr entender mejor una información.

En el tercer punto de la actividad de desarrollo del taller número dos, sobre la construcción de un texto, donde se entrega a cada estudiante una ficha con una información contenida en el diagrama de Venn, para que a partir de la imagen realizara un escrito con sentido completo; en algunos niños se nota mucha dificultad, pues solo extraen la información de tipo literal, en su mayoría no lograron la construcción de un escrito coherente.

La actividad de cierre está compuesta por cinco puntos que evaluarán el procedimiento para comprobar si fue efectiva la estrategia, para comprobar si los niños asimilaron la información. En un primer momento, los niños deben investigar sobre la clasificación de los seres vivos y elegir dos categorías, para luego clasificarlas en un diagrama de Venn. Seguidamente se les entrega una ficha, que contiene información sobre el león y el tigre, ellos a su vez deben leer en silencio la información para luego hacer una lectura en grupo. Posteriormente, se clasifica la información para completar una tabla y por último ubican el contenido de las similitudes y las diferencias encontradas en un diagrama de Venn, de esta manera se culmina la actividad con éxito, logrando que un alto porcentaje de los estudiantes obtuvieran muy buenos resultados y a su vez entender la importancia de este elemento, como una herramien- 
ta que les permite comprender la información de un texto y fortalecer la comprensión lectora.

En el taller 3 que se realizó con los estudiantes de tercero, se dio inicio con una discusión y una retroalimentación de los temas vistos anteriormente con los niños, como fue la línea de tiempo y diagrama de Venn, para luego inducirlos en un nuevo esquema, que les permitirá extraer información y organizarla de una mejor manera, en primer lugar se hace una conceptualización donde los niños toman apuntes y registros sobre la elaboración de este nuevo elemento, así mismo se explica que es una herramienta para estudiar o enseñar conceptos o ideas de una manera organizada y sintética, sin dar posibilidad a que se confundan, ya que al representarse por medio del sistema de llaves y tomar la forma de un diagrama o al verse organizados en filas y columnas habilita que se dé una fácil lectura y comprensión. Teniendo en cuenta las categorías de esta investigación las cuales están contempladas en el marco teórico de este estudio, como es la comprensión lectora y los subniveles que hace referencia a la lectura literal, inferencial y crítica. Se inicia la actividad de desarrollo de la tercera intervención pedagógica, en la que se procedió a entregarles a los niños una lectura sobre los seres vivos y los diferentes ambientes donde se desenvuelven, este material lo debían leer y clasificar la información para después plasmarla en un cuadro sinóptico, se les dio como referencia las diferentes causas de extinción, la mayoría logró ubicar la información de manera correcta en el esquema, la participación fue activa, el tema fue de gran interés para todos los niños, quienes dieron aportes muy valiosos, se observa que los niños están adquiriendo habilidades para desarrollar el pensamiento crítico y tener diferentes posturas con respecto al tema planteado en la figura 3, estudiantes de tercer grado en la actividad de cierre de la tercera intervención pedagógica sobre el taller de Cuadro sinóptico.

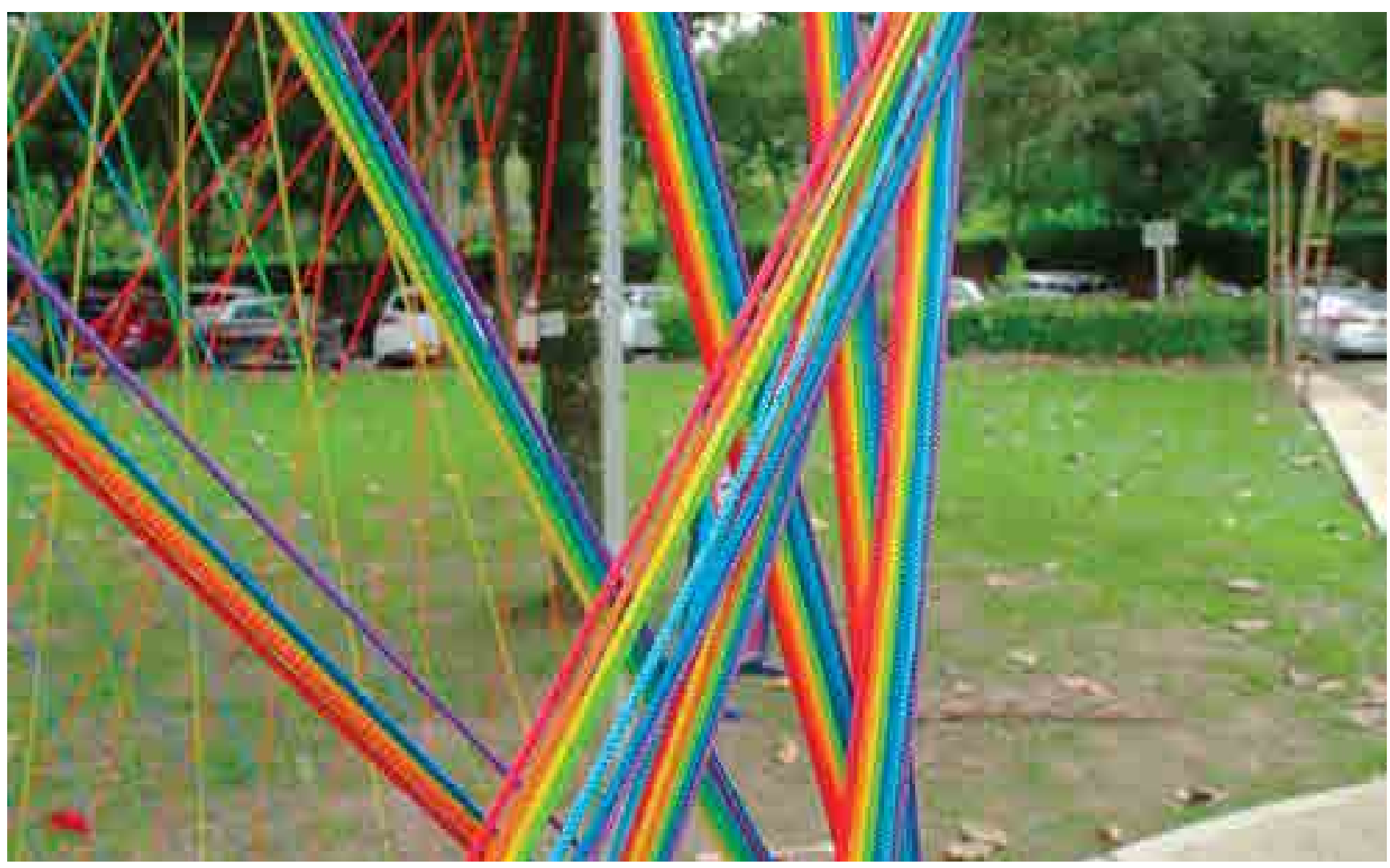

Proyecto Arcoíris. 
Teniendo en cuenta los objetivos planteados para esta actividad, podemos afirmar que el cuento es un recurso muy útil para desarrollar todo tipo de contenidos y enseñanzas que nos permitan afianzar los aprendizajes significativos de los estudiantes. Así pues, mediante el cuento, y después de un trabajo y una preparación previos de la estructuración del mismo para lograr su desarrollo efectivo, podremos trabajar y afianzar conocimientos y actitudes, tales como lograr que los estudiantes puedan comparar y contrarrestar, clasificar, tomar decisiones, proponer, argumentar y tener una postura crítica frente al tema de interés.

Para cerrar la actividad se planteó una sesión grupal en la que los niños comparten sus saberes, intercambian ideas y producen un cuadro sinóptico, además investigan sobre los signos de puntuación, se hace una socialización a través de un conversatorio, los niños en su gran mayoría levantan la mano, quieren participar y hablar de lo que aprendieron, en orden se les da la palabra. Luego entregan los trabajos para ser revisados y evaluar el logro de la estrategia.

Teniendo en cuenta los objetivos de esta investigación, fortalecer la comprensión lectora mediante diferentes estrategias, podemos afirmar que el cuento es un recurso muy útil para desarrollar todo tipo de contenidos y enseñanzas que nos permitan alcanzar la meta. Así pues, mediante el cuento, después de un trabajo y una preparación previos de la estructuración del mismo para lograr su desarrollo efectivo, podremos trabajar y afianzar conocimientos. Para dar comienzo a la actividad de la intervención pedagógica donde se trabajarán los tres niveles de lectura durante el transcurso del mismo. El taller se diseñó para cinco horas, en la actividad de inicio se dieron las orientaciones, se hizo la oración y posteriormente se lanzaron preguntas sobre qué saben ellos de los cuentos, cuántos conocen, y a quienes les gustan, la mayoría levantó la mano, todos querían participar y hablar, pues estaban ansiosos y se despertó la motivación.
Después de las intervenciones de los estudiantes se proyectó el cuento de los tres cerditos, los niños identificaron los personajes, se dialogó sobre cuál era el posible tema o valor que se resalta, a lo cual algunos respondieron que el esfuerzo valía la pena y también el valor de la solidaridad, porque los hermanos se ayudaron los unos a otros, y se salvaron del lobo. Después de hacer la inducción de la actividad y la motivación, los niños proceden a tomar apuntes de los pasos para elaborar un cuento, seguidamente a cada niño se le entrega una ficha que contiene la silueta de un cubo y unos personajes, objetos y lugares para que la coloren. En este momento de la actividad, hay mucha motivación, los niños colorean las fichas, observan las imágenes, hablan de las diferencias que hay de una ficha a la otra, después de colorearla hacen el segundo paso, recortan y arman el cubo. El diseño de este material tiene como propósito facilitarles a los estudiantes materiales para que realicen una escritura creativa, que produzca importantes logros en el desarrollo del conocimiento, es un espacio para que ellos compartan ideas, imaginen y se recreen con su trabajo, un gran número de los estudiantes está desarrollando las actividades en orden y siguiendo las orientaciones.

Figura 3. Estudiantes de tercero en la actividad de Desarrollo de la intervención 4

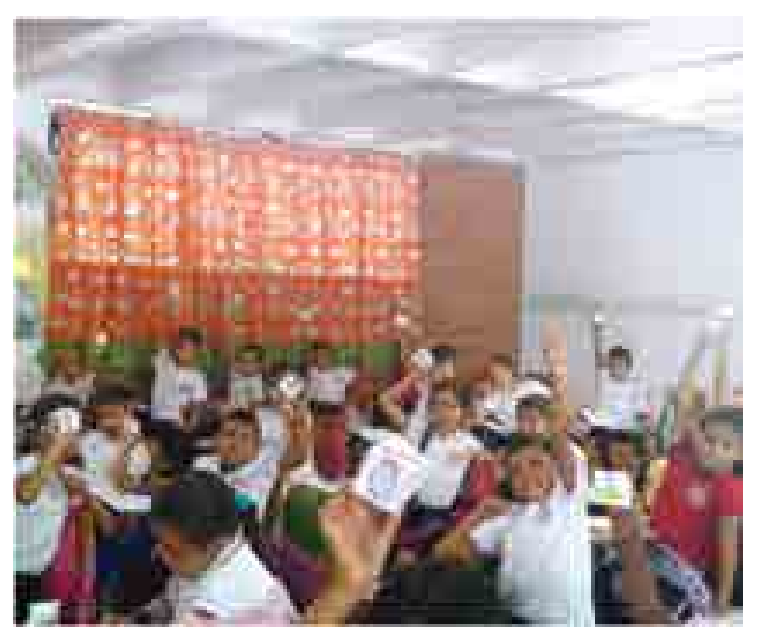


Después de armar el cubo, se hacen por grupos, de acuerdo con las diferentes categorías, en cada grupo se reúnen cubos que tengan como referencia lugares, objetos, personajes, para que entre todos armen un cuento, los niños en el grupo discuten, se les dificulta ponerse de acuerdo, algunos niños no les gusta trabajar en equipo, otros ponen muchas quejas porque no los dejan hacer nada, pasado un corto tiempo logran ponerse de acuerdo, los niños escribieron, fue muy lenta la actividad, cuando terminaron el cuento, el líder de cada grupo sale y comparte su escrito con los demás niños, se logró que todos escribieran, en las producciones textuales se evidencia creatividad. La construcción del cuento dentro de la estrategia pedagógica contribuyó a fortalecer la comprensión lectora, ya que después de analizar los indicadores de las categorías, mediante los instrumentos de observación como el diario pedagógico y las rejillas de evaluación, se pudo determinar que esta actividad es pertinente porque fue posible identificar, que los estudiantes establecieron relaciones entre imágenes, palabras y gráficos logrando una mejor comprensión en el nivel literal; el cuento en el nivel inferencial fue significativo, ya que partiendo de sus producciones escritas, manifestaron inferencias y relaciones coherentes sobre el contenido a partir de las imágenes dadas y, por último, en el nivel crítico los estudiantes hicieron intervenciones orales sobre sus producciones, y respondieron preguntas con su propia opinión.

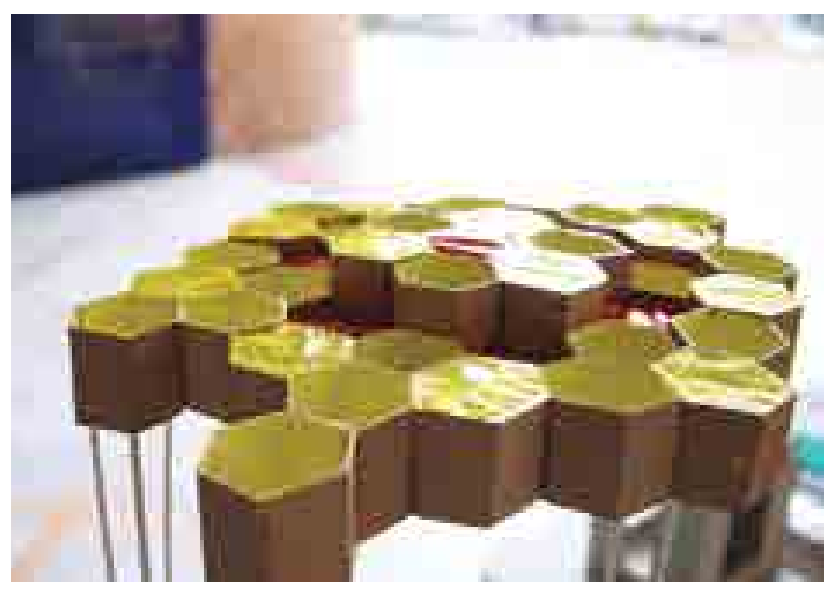

El desarrollo de la intervención pedagógica que tiene como objetivo que el estudiante identifique características y relaciones entre personas y objetos. El diseño de esta actividad siguió los parámetros de las categorías de esta investigación, relacionada con la comprensión lectora, proponiendo actividades que contribuyan para que los niños adquieran habilidades y destrezas en el saber, saber hacer y el ser.

La actividad se inicia con una lectura, relacionada con el tema "mi personaje favorito", luego de la lectura se hicieron preguntas de ¿cómo era Juanita?, ¿cómo era su cabello, su aspecto físico y su personalidad? Los estudiantes participan activamente respondiendo a las preguntas, además se les entrega un listado de adjetivos que le ayudaron al niño a tener una base para describir el personaje. En esta etapa la maestra explica los objetivos de clase y las razones por las cuales van a adquirir habilidades para leer y comprender mejor, se ilustra con ejemplos prácticos que les permitan a los niños una mejor comprensión y la conceptualización del tema.

Figura 5. Actividad de desarrollo del taller La descripción

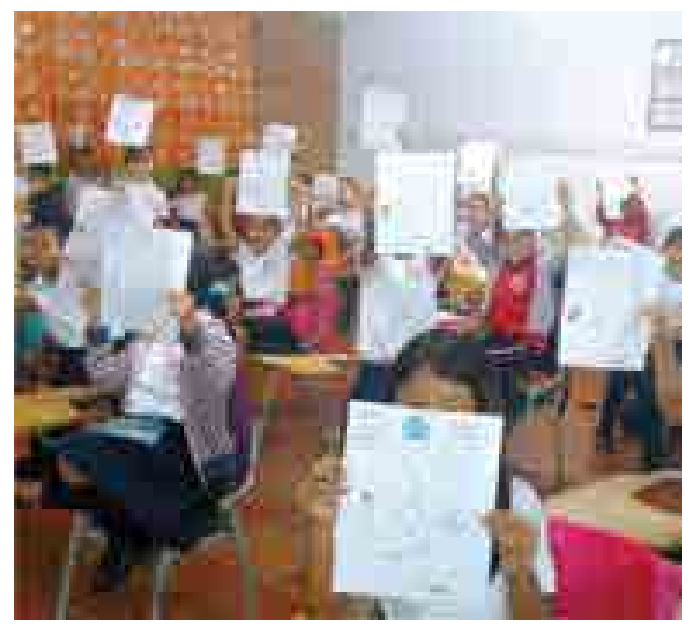

En la segunda etapa del taller, se les entrega a los niños una lectura corta sobre la "descripción que hace Lucía a su profesora de química", los niños se reúnen en grupos de dos, leen y 
dialogan entre ellos, luego tratan de dibujar a la profesora de química, según las indicaciones de Lucía, fue una actividad bastante agradable, porque permite mediante el proceso expresar ideas y compartir sus saberes, se mantiene la motivación y la creatividad, es propicia para afianzar la categoría del nivel crítico a través de su controversia con sus compañeros y adquieren nuevos aprendizajes.

En el inciso dos de la actividad de desarrollo, los niños continúan su trabajo en grupo, con una ficha que contiene la descripción de personas, para lo cual se les entrega una serie de adjetivos, de igual manera se les pide que hagan la descripción del profesor favorito que hayan tenido en su vida estudiantil y, por último, para cerrar la actividad, se les entrega a los niños una ficha para que hagan un plegable que contiene la descripción de un objeto.

La estrategia como lo plantea Solé antes de la lectura, ayudó a generar ideas sobre el tema e indagar y obtener la información que se requería para lograr la participación oral y escrita, los estudiantes fueron respondiendo las preguntas necesarias para lograr la construcción del concepto; durante la actividad de desarrollo identificaron y relacionaron ideas que les permitió una mejor comprensión lectora, también durante la actividad se dieron preguntas de tipo literal donde hacía referencia a ideas, datos y conceptos que aparecen en el texto y para el cierre se les pidió a los niños mostrar sus productos, en este caso la descripción de un objeto, a través de un plegable, donde se evidenció que la mayoría comprendieron la actividad y lograron obtener resultados favorables en el proceso lector.

\section{Análisis de las intervenciones pedagógicas grado sexto}

El objetivo desde las matemáticas en el grado sexto es fortalecer la comprensión lectora para mejorar el desempeño de los estudiantes en las diferentes pruebas internas como exter- nas. Por esta razón, en los talleres se desarroIlan actividades relacionadas con la comprensión de textos, también en los tres momentos propuestos por Isabel Solé: inicio, desarrollo y cierre. Con las actividades los estudiantes elaboran un portafolio de talleres matemáticos, como se aprecia en la siguiente figura.

Figura 6. Elaboración del portafolio de talleres matemáticos por los estudiantes del grado 601 de la institución educativa Fe y Alegría del municipio de Los Patios, Norte de Santander

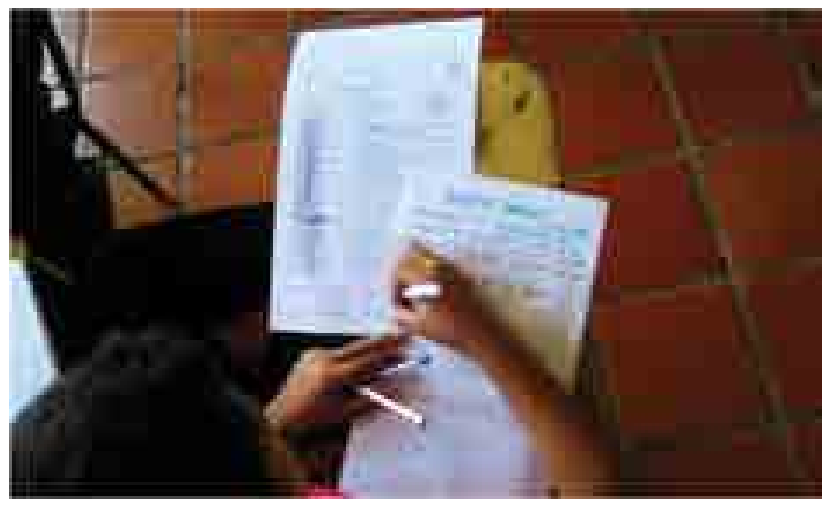

El taller 1, titulado "El edificio", cuyo objetivo es resolver situaciones que requieran de la suma y resta de números enteros, propone en la actividad de inicio la observación de una gráfica y la comprensión la hace el estudiante respondiendo unas preguntas de carácter literal e inferencial.

Los estudiantes al recibir la copia con las instrucciones del taller, no hacen lectura de las mismas y preguntan directamente al profesor sobre lo que deben hacer. La observación de la imagen facilita la comprensión de la utilidad de los números enteros en contextos reales, asimilando la numeración de los pisos del edificio como positivos y los subterráneos como negativos. No se evidenció dificultad en la solución de preguntas de orden literal e incluso con las inferenciales, pero sí con las del nivel crítico como ¿cuántas personas crees puedan trabajar en ese edificio? ¿Es necesario el ascensor, por qué? ¿Es suficiente un solo ascensor?; en donde se hace necesario más orientación 
por el docente. Hubo muy buena inferencia en el diseño del tablero de los ascensores. Aportó mucho al tema, porque se debía buscar la manera de diseñar un tablero con la menor cantidad de dígitos y que fuera útil para permitir el desplazamiento a todos los niveles, tanto para arriba como para abajo. Para el cierre, deben verificar la solución graficando las operaciones en la recta numérica. Después de la fase de comprensión, los estudiantes mostraron facilidad para resolver las situaciones empleando la suma y resta de números enteros, apoyándose en la gráfica del edificio y luego asimilándolo con la recta numérica.

Figura 7. Imagen con propuesta de un estudiante sobre los controles del ascensor del edificio como parte de la comprensión lectora

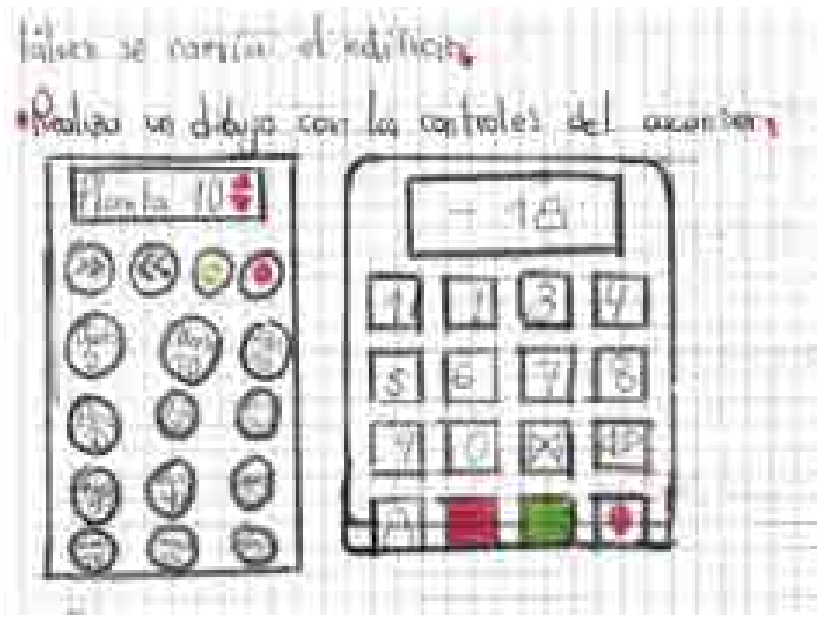

Una vez terminado el taller se concluye que: la inclusión de imágenes dinamiza la comprensión de los textos. Es pertinente para los próximos talleres solicitar a los estudiantes el uso del diccionario para buscar el significado de términos desconocidos y desarrollar la noción de polisemia del idioma a partir de la contextualización del léxico. Es evidente que esta terminología debe ser dominada por el docente o la docente y llevada a la práctica por el estudiante con abstracciones implícitas. Aunque la estructura del taller puede mejorar, esta contribuyó con la comprensión para hallar la solución a las situaciones matemáticas. Es recomendable que el taller se desarrolle en su totalidad en las clases, para evidenciar que son los estudiantes quienes lo elaboran. Se debe reforzar permanentemente la redacción de respuestas con oraciones completas y el uso de las normas ortográficas. El resultado de la evaluación individual evidencia que la tercera parte de los estudiantes se encuentra en el nivel literal de lectura y en menor proporción en el inferencial.

Figura 8. Planteamiento que hace el estudiante para resolver las situaciones

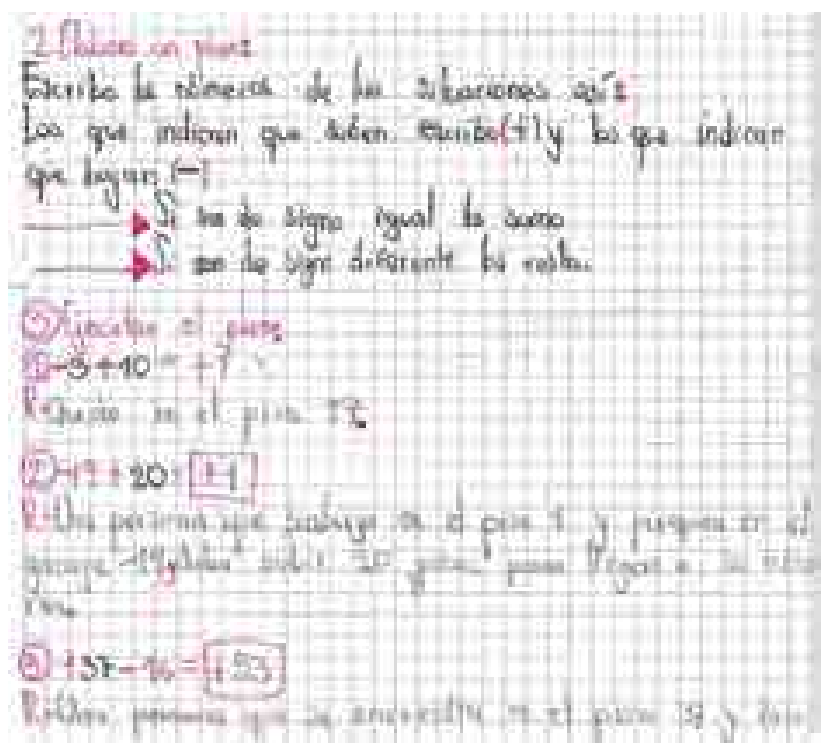

Figura 9. Actividad de inicio del taller 2, Elaboración de glosario

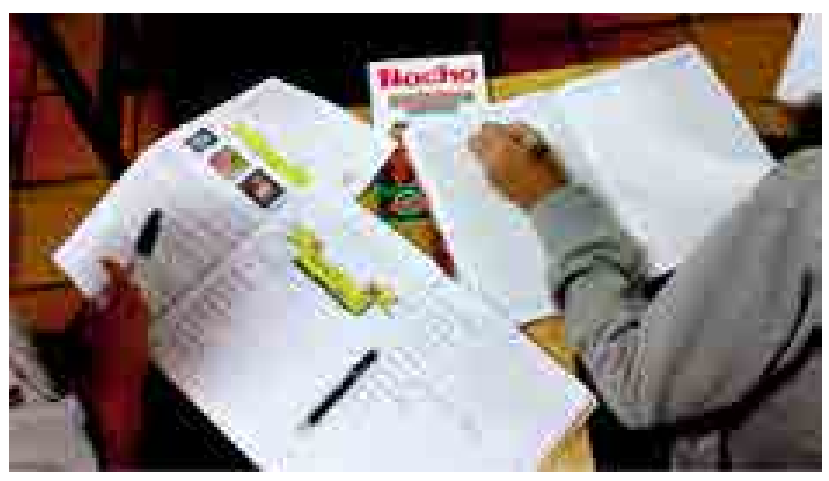

A nivel grupal se hizo la lectura, lo cual permitió que cada estudiante participara voluntariamente dando respuesta a las preguntas de la comprensión. En general los estudiantes se mostraron muy atentos a las participaciones y comentarios de sus compañeros, lo que significa que el tema fue de su interés. Luego, en 
el desarrollo, debe dar solución a unas situaciones en donde debe hallar la diferencia de temperaturas. Los estudiantes no presentaron dificultad para resolver las situaciones de la actividad de desarrollo en razón a que estas estaban relacionadas con la información de la lectura "Animales extremos".

Para el cierre, el taller presenta otras situaciones de las cuales se hizo una evaluación escrita de control del proceso. Causó curiosidad las situaciones relacionadas con las fechas antes de Cristo. Lo anterior motivó a los estudiantes a preguntar y hacer comentarios con respecto a varios temas, incluso el religioso.

Figura 10. Solución de situaciones en actividad de desarrollo y cierre del taller 2 de los estudiantes de sexto grado

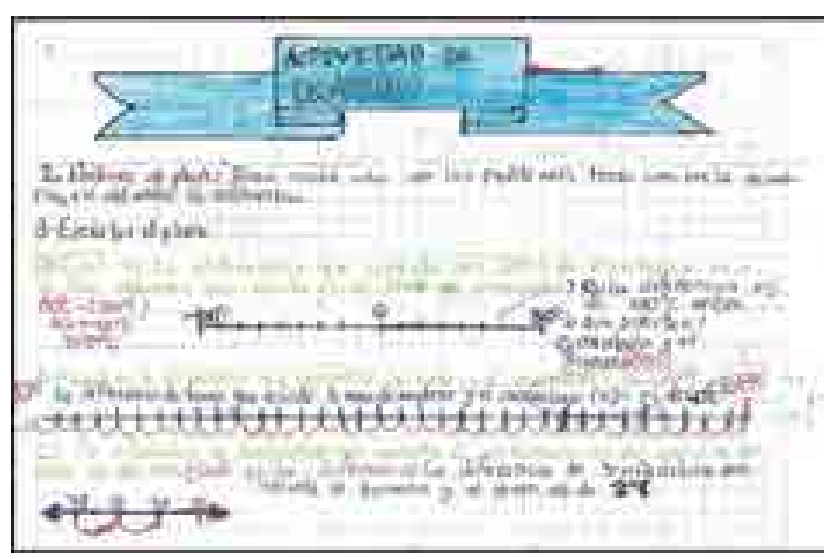

Al terminar las actividades del taller, el docente concluye que el texto sobre datos científicos fue de fácil comprensión para los estudiantes y les motiva a participar con sus opiniones e interrogantes, porque ya la clase de matemáticas no es solo de operaciones y números. En el desarrollo de la evaluación escrita se pudo apreciar que los estudiantes en la comprensión obtienen los datos y los grafican, pero hay dificultad en la inferencia para plantear la solución. La mitad no alcanzó el nivel literal, tal vez por la complejidad del concepto de diferencia entre números enteros, pero la otra mitad alcanzó el inferencial y literal en menor proporción.
Figura 11. Taller 3. Conceptualización de la multiplicación partiendo de la suma

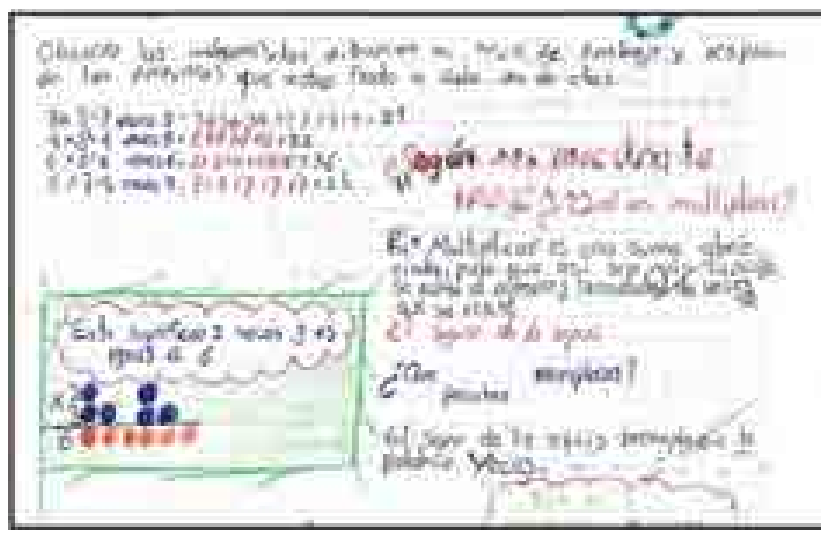

El taller 3 titulado "La ley" cuyo objetivo es aplicar la ley de los signos en la multiplicación de números enteros; la actividad de inicio muestra unas gráficas relacionadas con el proceso de la multiplicación como suma abreviada. Frente a cada gráfica se plantea una pregunta que indaga sobre los presaberes con respecto a la multiplicación y el significado de los símbolos de la misma (la equis y el punto), el objetivo fue que los estudiantes reemplazaran los símbolos por palabras, relacionando lo matemático con el lenguaje como reemplazar la " $X$ " por la palabra veces.

El docente explica a todos los estudiantes la interpretación de la relación entre positivo con derecha y negativo con izquierda a su vez con la intervención de la palabra "veces".

Figura 12. Interpretación de la ley de los signos en lenguaje cotidiano

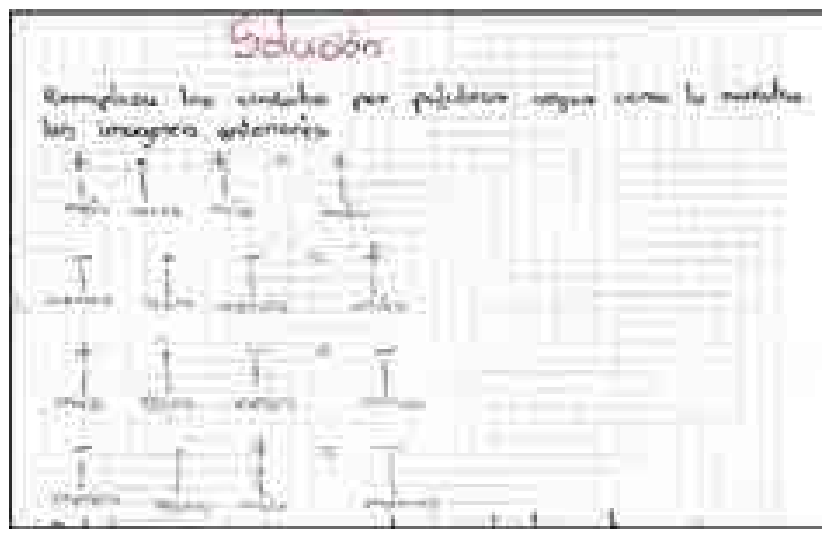


En el desarrollo se plantean unas multiplicaciones entre números enteros con diferentes signos para que los niños identifiquen la diferencia en los signos. En la actividad de cierre se hace una evaluación donde los estudiantes deben graficar las multiplicaciones entre números enteros para identificar las diferencias por la multiplicación de los signos. Los estudiantes mostraron dificultad para identificar patrones de las imágenes, muestran debilidad para realizar inferencias de los textos con contenidos netamente matemáticos. El docente pregunta a los estudiantes sobre qué actividades les gustaría que se desarrollaran en los talleres y sugieren se incluyan más gráficos y actividades para colorear.

Al terminar el taller se concluye que el no incluir textos con información relacionada con el tema, lo cual fue una desventaja porque las lecturas en los anteriores talleres fueron motivo de diálogo en la clase sobre el tema y su aplicación en otras áreas del saber. Por lo anterior, es necesario hacer refuerzo del tema "la ley de los signos" en el siguiente taller y adicionando la multiplicación de números enteros. Como resultado de la evaluación del taller se obtiene que más de la mitad alcanza el nivel literal y se mantiene el inferencial.

El taller 4 titulado "Apliquemos la ley" cuyo objetivo es aplicar la ley de los signos en la multiplicación de números enteros, en refuerzo al taller anterior. En la actividad de inicio los estudiantes buscan en el diccionario el significado de Ley para asociarlo con la ley de los signos. Luego, observan la imagen recordando la ley de los signos, asociando los colores con los resultados, así: positivo con el color verde y derecha, negativo con el color rojo e izquierda. La comprensión lectora se hace con un texto con pictogramas, donde se expone una situación de conflicto entre los signos positivos y negativos. Los estudiantes deben transcribir el texto, ilustrar la situación y proponer la solución al conflicto. Una buena alternativa es aplicar la ley de los signos.
Figura 13. Ilustración del conflicto entre los positivos y negativos por un estudiante de 601

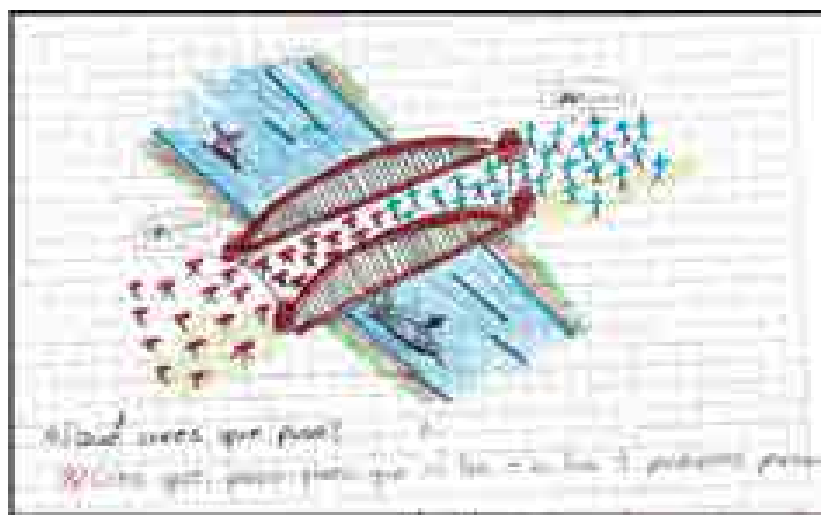

Seguido a lo anterior, los estudiantes deben escribir los pasos para multiplicar los números enteros con base en la observación de una gráfica que lo explica. Como práctica lúdica de la multiplicación de números enteros, se hace una actividad de coloreado, en la que los estudiantes resuelven unas operaciones combinadas con signos de agrupación para obtener el número entero asignado al color. La comprensión lectora implica también retener y almacenar información como resultado de un buen entendimiento, ya que forma parte del proceso de aprendizaje significativo.

Figura 14. Actividad de coloreado con clave, aplicando la multiplicación de números enteros

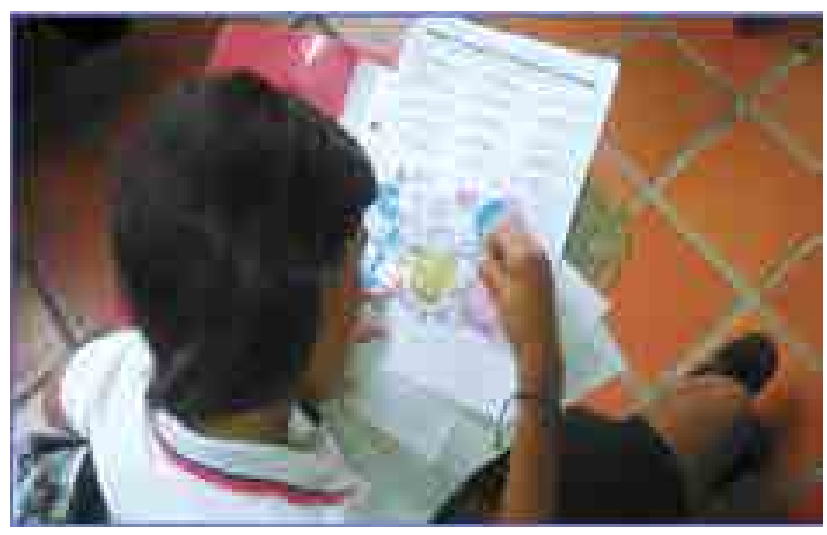

Los estudiantes asocian los colores con el semáforo y gusta más el verde por el sentido positivo. El conflicto de los signos permitió la inferencia de los estudiantes. Las opiniones se dieron desde el punto social y matemático. Lo 
anterior, permitió mayor claridad en cuanto a la aplicación de la ley de los signos. A su edad todavía les agradan las actividades de colorear. Para la solución de los problemas, la mayoría de los estudiantes prefieren graficar.

Se llevó a cabo una actividad de medición de temperaturas, empleando termómetros del laboratorio de química, estos traen una escala amplia desde $-10^{\circ} \mathrm{C}$ hasta $110^{\circ} \mathrm{C}$, siendo muy útiles para la medición de temperaturas extremas.

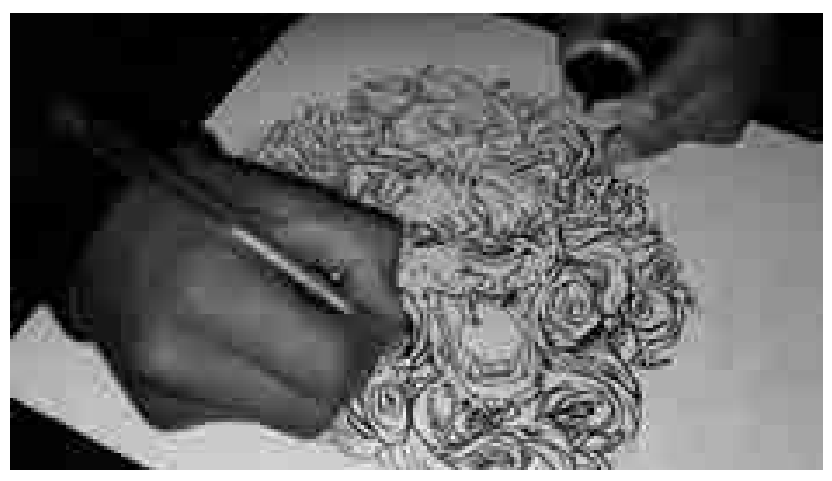

También cada estudiante traía un termómetro sencillo para medir su temperatura corporal. Así, la actividad permite mejorar la comprensión lectora y las matemáticas pues se relacionan profundamente a través del lenguaje común traducido a conceptos matemáticos para poder dar solución a lo que se busca, un error de interpretación puede cambiar completamente el resultado. La comprensión es imprescindible porque es el instrumento que permite establecer el planteamiento y proceso de datos correctos. En la actividad de desarrollo, se presenta el texto de tres problemas, en donde la mejor alternativa de solución es la multiplicación, pero el estudiante propone la solución que más se le facilite. Para el cierre se plantean ejercicios de operaciones combinadas con números enteros con signos de agrupación y problemas en texto para su solución. Lo anterior, para preparar la evaluación escrita. Una vez terminado las actividades del taller, se aplica la evaluación escrita individual.
Figura 16. Medición de temperatura corporal

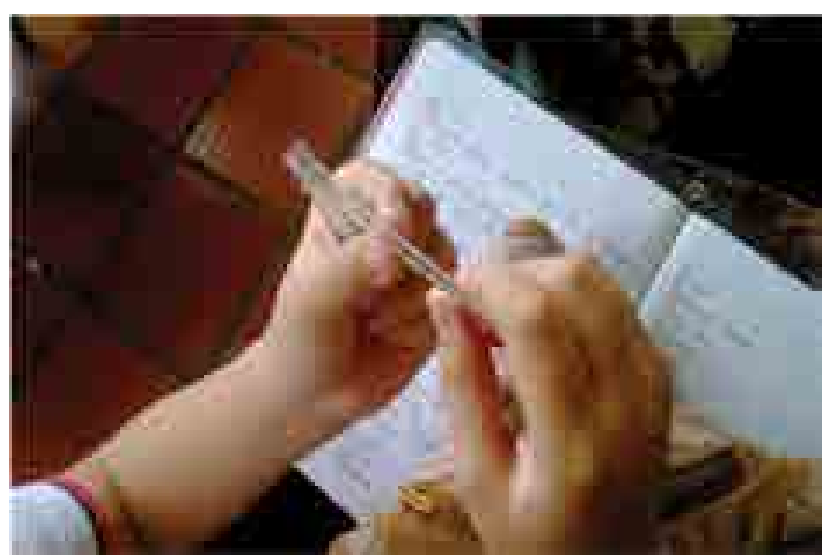

Se mostraron muy atentos en la experiencia de medir la temperatura del agua hirviendo y del agua con hielo. Les llamó la atención observar cómo en los termómetros del laboratorio de química subía y bajaba el mercurio. La actividad facilitó que algunos estudiantes propusieran hipótesis con respecto a ¿qué sucedería si cambiamos los termómetros de recipiente? (caliente a frío y viceversa).

Uno de ellos solicitó la autorización del profesor para introducir su termómetro en el agua caliente para ver qué sucedía. El estudiante lo hizo con las precauciones del caso. El termómetro se rompió y esto permitió la inferencia de ideas alrededor de buscar la razón. Una vez terminado el taller el docente concluye que la lectura en donde se personifican los números enteros facilitó la inferencia de los estudiantes.

La combinación de lo matemático con el dibujo coloreado, les agrado. La medición de la temperatura corporal, agua hirviendo y agua con hielo, facilitó notablemente la inferencia en los estudiantes, como se evidencia en los resultados de la evaluación escrita del taller. De los 42 estudiantes: 05 no alcanzan el nivel literal de lectura, 17 llegan al nivel literal, 16 llegan al nivel inferencial y 4 llegan al nivel crítico. Hubo un aumento considerable en el nivel inferencial de más del doble de estudiantes en comparación con el taller anterior. 
La experiencia con la medición de temperaturas con los termómetros del laboratorio de química, motivó la participación de los estudiantes, porque con ellos evidenciaron cómo la temperatura sube y baja, asimilando más el concepto de diferencia con respecto a la temperatura ambiente. Es notoria la contribución de experiencias significativas previas a los textos relacionados con las temáticas. Se evidencia en los resultados de la evaluación del taller el aumento del nivel inferencial y en menor proporción en el nivel crítico.

El taller 5, titulado "Coordenadas" cuyo objetivo fue ubicar coordenadas en el plano cartesiano utilizando los números enteros, este propuso para el inicio el juego del plano cartesiano en el patio, formado por todos los estudiantes del grupo. Cada estudiante tenía un número entero y debía ubicarse en el lugar que le correspondía dependiendo del valor absoluto y relativo.

Figura 17. Juego del plano cartesiano en el patio realizado por los estudiantes de 601, Taller 5

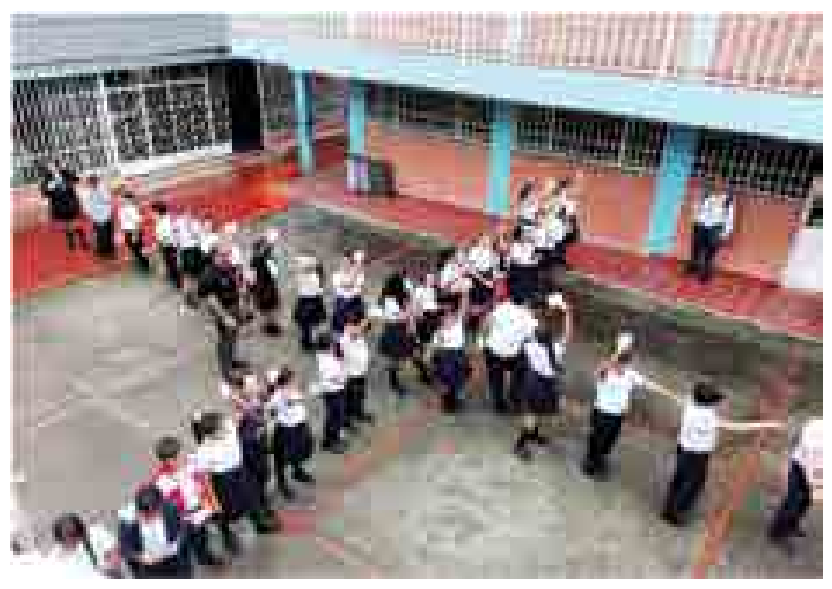

La salida del aula a un patio para representar el plano cartesiano con los estudiantes fue muy agradable para todos los participantes. El solo hecho de salir del aula en la clase de matemáticas es novedoso para ellos. La buena actitud facilitó la comprensión de la ubicación de los números enteros en los ejes del plano cartesiano, al igual que el concepto de coordenada. Para la actividad de desarrollo se muestra una figura geométrica en el plano cartesiano para identificar las coordenadas que la forman y el estudiante debe identificar las nuevas coordenadas de acuerdo con el desplazamiento indicado.

Al graficar en el tablero el plano y los números enteros, los estudiantes lo asocian inmediatamente con las coordenadas que se formaron en el patio. Por lo tanto, la ubicación de figuras en el plano fue fácil. En el cierre, también, con base en una figura geométrica en el plano, el estudiante debe resolver preguntas con respecto a las coordenadas que forman la figura y sus medidas.

Figura 18. Refuerzo de la actividad de desarrollo en el tablero por el docente

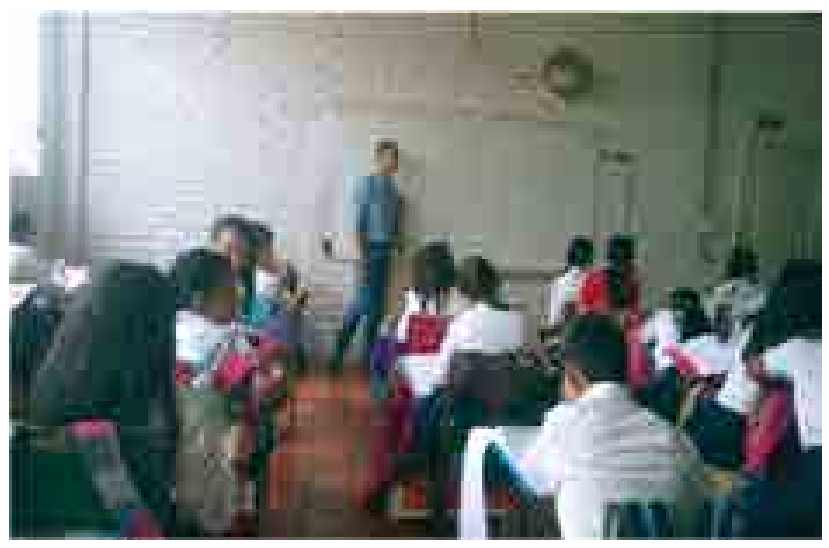

En el cierre no hubo ninguna dificultad con respecto a las preguntas basadas en la interpretación de las figuras geométricas en el plano. Se realizó evaluación sobre el plano cartesiano basada en la interpretación de unas gráficas estadísticas (que no se había incluido en el taller) y el resultado fue muy bueno.

Figura 19. Parte de la evaluación individual del Taller 5

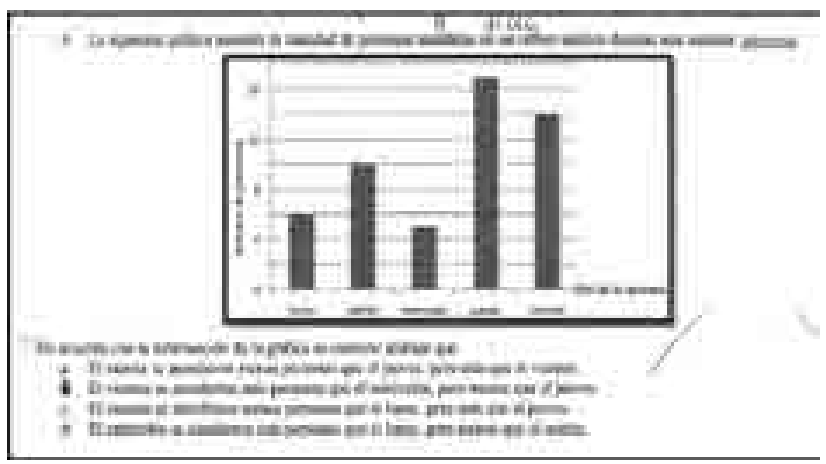


Al terminar las actividades del taller, el docente concluye que realizar una actividad práctica y lúdica que represente situaciones relacionadas con el tema matemático, facilita la comprensión de los diferentes textos de situaciones matemáticas. El resultado de la evaluación individual fue: 2 estudiantes no alcanzan el nivel literal de lectura, 11 alcanzan el nivel literal, 22 alcanzan el nivel inferencial, 6 alcanzan el nivel crítico ( 1 estudiante faltó el día de la prueba). La mitad de los estudiantes alcanzaron el nivel inferencial y una cuarta parte el literal.

Tanto en el taller anterior como en este, la experiencia significativa previa a las lecturas, eleva considerablemente la inferencia en los estudiantes.

El taller 6 titulado "Compartir" cuyo objetivo fue diferenciar en las fracciones la relación mayor, menor y equivalencia, en su fase de inicio cada niño trajo una arepa, pizza, torta o comestible circular de $20 \mathrm{~cm}$ de diámetro. Formaron grupos de 5 estudiantes para seguir las instrucciones del profesor. Se indicó que un niño partiera la torta en dos partes iguales, luego otra en tres, cuatro, seis y ocho. Con base en la división de las tortas se recordó el concepto de fracción, se compararon las fracciones para identificar las mayores y menores como también la equivalencia. La aceptación de la actividad fue del $100 \%$, todos los niños trajeron a la clase un comestible según las indicaciones del profesor días antes. La atención y la interacción fueron plenas. Con gran facilidad recordaron la representación de fracciones e identificaron las diferencias en los conceptos de mayor, menor y equivalencia.

Luego, los estudiantes consumieron los alimentos compartiendo fracciones diferentes. Como complemento de la actividad el profesor representó gráficamente con apoyo del video beam, el fraccionamiento de los comestibles.

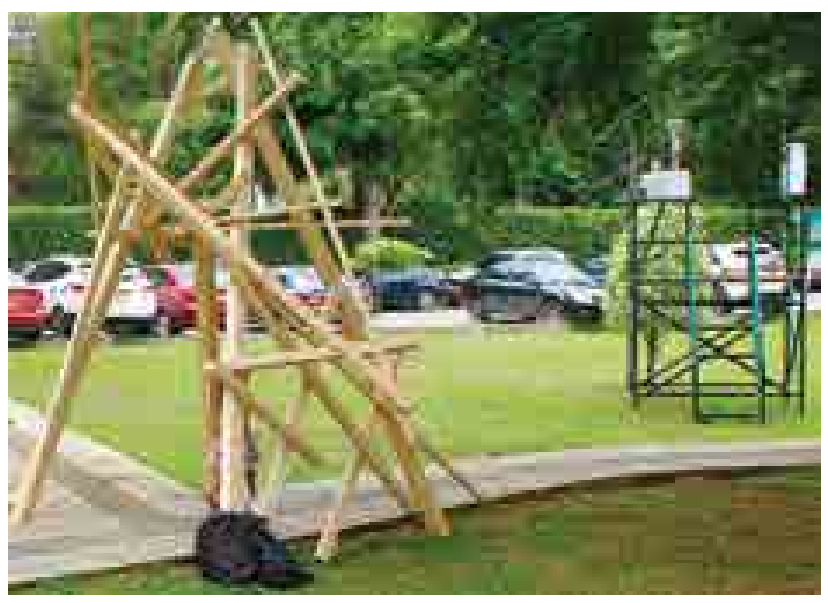

La socialización en el momento de intercambiar fracciones de alimentos con los otros compañeros fue excelente, este momento fue muy tranquilo por lo tanto agradable. En la etapa de desarrollo, los jóvenes debían leer un texto con la explicación de las partes de la fracción y la denominación de cada una. Con base en lo anterior, graficarían lo que hicimos con los alimentos y representaría numéricamente.

Figura 21. Representación del fraccionamiento de los alimentos

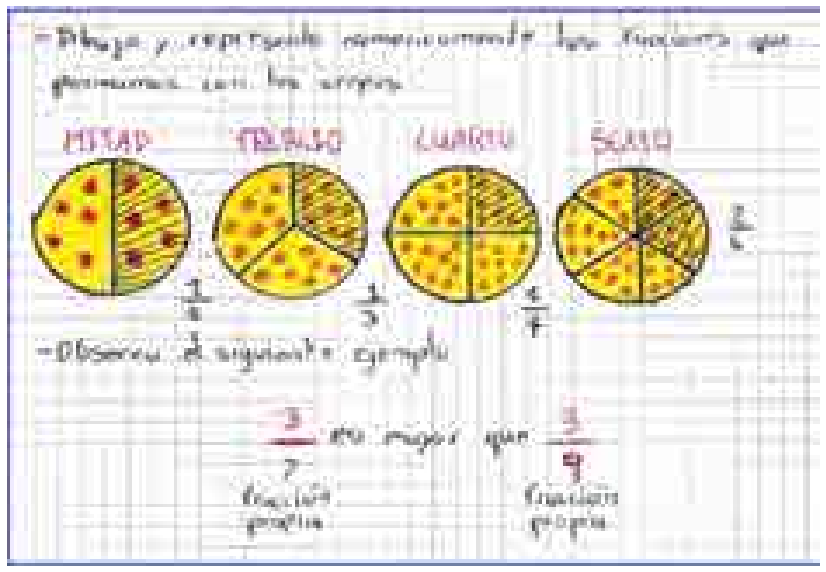

La comprensión del texto se hizo sin dificultad porque lo asociaron con el reparto de los alimentos. Todos los estudiantes graficaron las fracciones de los alimentos y su representación numérica sin ninguna dificultad. En el cierre, resolverían una situación que describe 
el reparto de unos caballos en mitad, tercios y novenos como resultado de una herencia. Se formularon preguntas con respecto al planteamiento de la situación.

La actividad de cierre fue resuelta por la mayoría de estudiantes, haciendo el reparto según el texto. Se hizo una evaluación individual en la que se planteó una situación en una pizzería. Con base en esta, se hizo una pregunta literal, tres inferenciales y una crítica. Hubo más preguntas inferenciales en razón a que en los talleres anteriores el alcance del nivel inferencial de lectura fue mayor.

Figura 22. Solución gráfica en la actividad de cierre

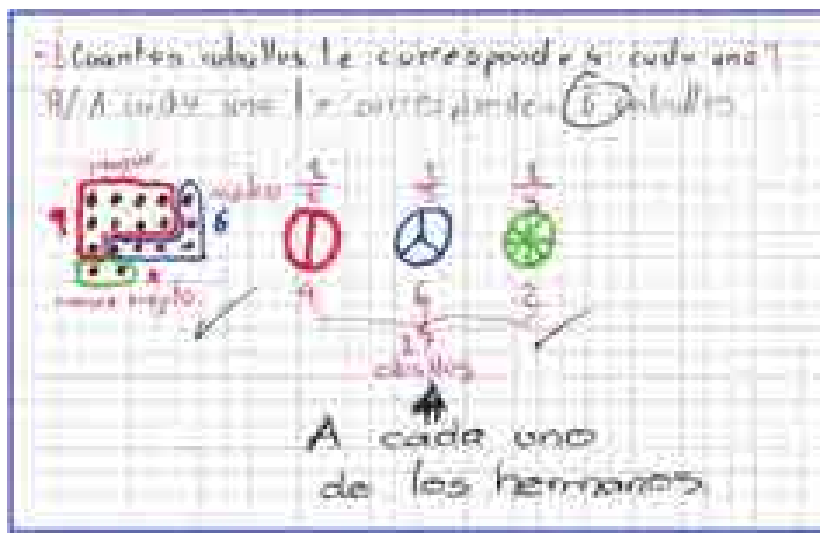

Al terminar el taller, el docente concluye que la vivencia del reparto de los comestibles, en definitiva, fue significativa, en cuanto al aprendizaje de la identificación y diferenciación de fracciones.

Figura 23. Respuesta de un estudiante a una pregunta de nivel crítico

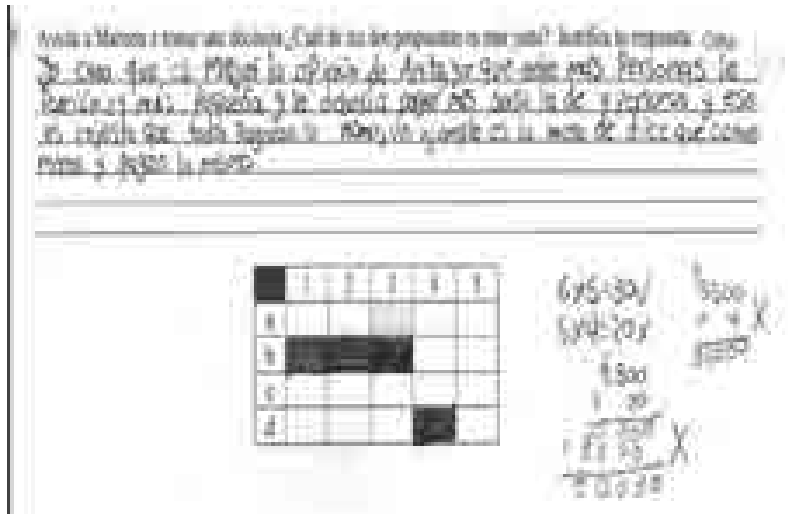

La experiencia en una actividad práctica previa a la lectura facilita la inferencia y hasta el nivel crítico. El resultado de la evaluación individual fue muy positivo. De los 42 estudiantes: 5 no alcanzan el nivel literal de lectura, 6 alcanzan el nivel literal, 25 alcanzan el nivel inferencial y 6 alcanzan el nivel crítico. Más de la mitad de los jóvenes del grupo superan el nivel literal de la lectura.

\section{Conclusiones}

Finalizada la investigación y realizado el análisis de los instrumentos para la recolección de la información, se culminó con éxito, logrando los objetivos y dando respuesta a la pregunta de investigación, ¿Cómo fortalecer la comprensión lectora desde las áreas de matemáticas y lenguaje en los estudiantes de tercero de primaria y sexto de la institución educativa Colegio Integrado Fe y Alegría del municipio de Los Patios, Norte de Santander?, se llega a las siguientes conclusiones:

La implementación de los talleres pedagógicos mediante estrategias didácticas, arrojó resultados favorables para ser aplicados en el aula de clase, como una oportunidad de incluir y adecuar en el proceso de lectura herramientas que posibiliten una forma dinámica de acercarse espontáneamente a ella. La estrategia pedagógica se constituye como una metodología fundamental, en la que con la implementación y animación de diferentes textos, como los esquemas mentales, los cuentos, fábulas, leyendas, entre otros y los problemas matemáticos dados en textos o gráficos se constituyen en un recurso didáctico útil en los diferentes escenarios educativos y contextualizados para los estudiantes, desarrollando habilidades importantes para el proceso lector.

En cuanto a lo metodológico, la implementación de los talleres permitió la reflexión que nos da las herramientas de una investigaciónacción cualitativa a los maestros en las aulas de clase para ser investigadores e innovadores, 
abiertos al cambio, ya que con estos procesos se logran avances significativos en los estudiantes como el goce de la lectura, en donde los jóvenes son más participativos y conversadores, hacen hipótesis sencillas y espontáneas que favorecen la inferencia y representaciones gráficas que le contribuyen a resolver situaciones de la vida cotidiana. Lo anterior se logra con intervenciones pedagógicas sistemáticas, como lo muestra este estudio, en el que el análisis de instrumentos, como el diario pedagógico, la rejilla de evaluación y las pruebas evidencian cómo los pequeños lectores superan gradualmente el nivel literal de lectura, abordándola con agrado, cuando esta va acompañada de actividades prácticas y tangibles en donde comparte con sus compañeros, que definitivamente favorece el clima escolar, siendo esto muy motivante y como resultado, los aprendizajes son significativos lo que contribuye directamente a mejorar su actitud frente a la lectura.

Para dar respuesta al primer objetivo específico de esta investigación se aplicó una prueba diagnóstica y se analizaron los resultados de las Pruebas Saber 2015 y 2016 de los grados tercero y quinto, con el objetivo de identificar los niveles de comprensión de lectura, en la población objeto de este estudio, mostrando que los estudiantes en su mayoría presentaban un bajo nivel en la lectura literal, inferencial y crítica.

Así mismo, para dar respuesta al segundo objetivo específico de este estudio, se diseñaron diferentes talleres pedagógicos con actividades que permitieron fortalecer los niveles de comprensión lectora desde el área de lenguaje en tercer grado y matemáticas en sexto. Se pueden considerar una herramienta para fomentar los niveles de comprensión lectora, porque permite que el estudiante tenga mejores resultados académicos en las diferentes áreas del conocimiento.

Evaluados los resultados finales y comparados con el diagnóstico, como lo plantea el tercer objetivo específico, en cuanto a la valora- ción de la intervención pedagógica, esta estrategia didáctica mostró resultados favorables, tanto en los estudiantes de tercer grado como de sexto, debido a que el proceso de aprendizaje impactó la autoestima y la confianza en el aula con respecto a la forma de aprender. Al inicio se observó desinterés, desmotivación e indisciplina, pero con el desarrollo de los talleres estos comportamientos fueron mejorando, y el trabajo en equipo desarrolló la emotividad por las actividades. Es relevante que al aplicar diferentes estrategias los estudiantes reconozcan un mejor desempeño académico, que se traduce en unas mejores relaciones escolares, por ende; el reconocimiento social produce una evolución en la autoconfianza y autoestima de los niños, condición necesaria para el éxito escolar.

Desde el punto de vista didáctico, la enseñanza con esta estrategia permitió observar que la comprensión lectora representa un reto para los docentes, ya que los sitúa en el campo de la reflexión sobre la enseñanza, sobre la emergencia que significa aplicar mecanismos eficientes al proceso de aprendizaje de los estudiantes y la necesidad de devolverles poco a poco la responsabilidad de planear, monitorear y evaluar sus propios procesos y actuaciones.

Finalmente, compartimos los resultados generales de esta investigación, al propiciar situaciones auténticas con sentido para los estudiantes, mediante las intervenciones pedagógicas que favorecieron la motivación en los procesos de aprendizaje con actividades didácticas contempladas en la estrategia pedagógica "tipología textual y problemas matemáticos" como un método de enseñanza en el contexto educativo de una forma integral, que nos permitieron seguir de cerca el proceso de aprendizaje, ejerciendo la activación del conocimiento. La investigación partió de la necesidad de superar la lectura literal permitiendo a los estudiantes apropiarse del acto lector como una práctica sociocultural. El estudio está diseñado en diferentes momentos 
con relación en el antes, el durante y el después del proceso lector con el fin de encaminar al estudiante a ser crítico reflexivo y para que mejore sus resultados académicos, y esto se verá reflejado en las pruebas externas y en el índice sintético de calidad.

Con este estudio se puede afirmar que la aplicación de las diferentes actividades que se plantearon en los talleres pedagógicos desde las áreas de lenguaje y matemáticas, como estrategia para fortalecer la comprensión lectora fue significativa; frente a una situación de apatía y desmotivación hacia la lectura de textos por parte de los niños, la implementación de la estrategia movilizó no solo la motivación hacia este tipo de actividad, sino la comprensión en algunos niveles de profundidad de los contenidos de los textos.

\section{Recomendaciones}

A continuación presentamos algunos aportes que, en el trascurso de esta investigación, se han observado y creemos pertinentes para tenerlos en cuenta en el proceso de las prácticas pedagógicas, como en el desarrollo de talleres para el fortalecimiento de la comprensión lectora, con el fin de lograr un mejor nivel académico y en la vida social de nuestros estudiantes. Estas recomendaciones están dirigidas a instituciones educativas, docentes, padres de familia y todas las personas que estén interesadas en favorecer el aprendizaje significativo mediante la aplicación de estrategias que favorezcan la comprensión lectora.

Las actividades de los talleres se deben programar para realizarlas en sesiones o clases de forma continua, es decir, sin interrupciones, en lo posible en dos horas de clase. Lo anterior, en razón a que tanto en lenguaje como en matemáticas, generalmente la intensidad semanal está entre cuatro y cinco horas de clase, repartidas en dos horas por día, como máximo, entonces, cuando las actividades de un taller son de más de dos horas se harían en por lo menos dos días y puede darse la situación que se realicen algunas actividades institucionales como izadas de bandera, reuniones de docentes con padres de familia, capacitación de docentes y jornadas sindicales, entre otras, que no permitan llevar a cabo la clase siguiente en la que se terminaría el taller, por lo tanto el proceso sería menos eficiente.

Antes de abordar la comprensión de un texto, la programación de una actividad práctica grupal, con carácter lúdico, relacionada con la temática de la clase, en donde los estudiantes comparten con sus compañeros, profesor y hasta con la vinculación de padres de familia, en donde la participación en la observación al manipular elementos que le facilitan comprender las situaciones previas a los textos, son definitivamente significativas en el aprendizaje de los estudiantes, porque facilitan la contextualización de los saberes y la comprensión lectora.

Toda habilidad humana se adquiere y mejora con la práctica, la comprensión lectora no es la excepción, a mayor práctica en lectura mejor comprensión. Si en todas las áreas del conocimiento que se trabajan con nuestros estudiantes, se implementan estrategias didácticas para favorecer la comprensión lectora, acompañadas de experiencias significativas previas, el resultado académico se enriquecería notablemente.

Aunque como docentes nuestra meta es contribuir para que nuestros estudiantes alcancen los tres niveles de lectura, consideramos según la experiencia con este estudio que para el grado tercero alcanzar el nivel literal y el inferencial para grado sexto, es acorde a su edad y nivel académico, aunque algunos niños y jóvenes los superan pero en menor número y en la medida que se trabaje con estrategias pedagógicas como estas, la tendencia será al mejoramiento y formaremos personas con pensamiento crítico a menor edad y grado escolar.

Como docentes investigadores evidenciamos la gran utilidad de la investigación-acción 
como herramienta fundamental para el mejoramiento de las prácticas pedagógicas, porque nos permite identificar problemas de nuestros estudiantes, proponer alternativas de solución con las intervenciones pedagógicas, implementarlas, hacer seguimiento con instrumentos para el registro de la información, reflexionar sobre la marcha y mejorar los procesos; pero, lo que consideramos más útil de este tipo de investigación es que permite el mejoramiento continuo organizado, por lo anterior, estudios de esta clase son pertinentes en todos grados desde preescolar hasta educación media.

\section{Referencias}

Ander-Egg, E. (1991). El taller como sistema de enseñanzaaprendizaje. Buenos Aires: Magisterio Río de La Plata.

Arango, L., Aristizábal, N., Cardona, A., Herrera, Z., \& Ramírez, O. (2015). Estrategias metacognitivas para potenciar la comprensión lectora en estudiantes de básica primaria. Manizales: Universidad Autónoma de Manizales.

Bernal, L. (2014). Mejoramiento de la comprensión lectora en estudiantes de cuarto grado de básica primaria mediante el desarrollo de estrategias cognitivas con el apoyo de un recurso TIC. Bogotá: Universidad de la Sabana.

Betancourt, M., \& Socorro, E. (2015). La enseñanza para la comprensión como didáctica alternativa para mejorar la interpretación y producción oral y escrita en lengua casteIlana en el grado quinto del Centro Educativo Municipal La Victoria de Pasto. Universidad de Manizales, Facultad de Ciencias Sociales y Humanas.

Bueno, D. (2012). Propuesta metodológica para mejorar la interpretación de análisis y solución de ejercicios y problemas matemáticos en los estudiantes de quinto grado de la institución educativa Alejandro Vélez Barrientos. Medellín: Universidad Nacional de Colombia.

Congreso de la República. (1991). Constitución Política de Colombia. Bogotá: Presidencia de la República.

Congreso de la República. (1994). Ley General de Educación Ley 115. Bogotá: Presidencia de la República.

Contreras, Y. (2015). Prácticas pedagógicas que desarrollan la competencia comunicativa desde el fomento de la comprensión lectora en los estudiantes de tercer grado de la institución educativa Eustorgio Colmenares Baptista. Cúcuta: Universidad Francisco de Paula Santander.

Duarte, W. (2017). Fortalecimiento de la comprensión lectora en el área de Ciencias Naturales en grado quinto CER, Sucre, municipio de Mutiscua, Norte de Santander. Bucaramanga: Universidad Autónoma de Bucaramanga.

Elliot, J. (2000). El cambio educativo desde la investigación acción. Madrid: Morata.

Feixas, G. (1996). Manual de la técnica de rejillas. Barcelona, Buenos Aires, México: Paidós.
Galvis, M. (2017). Diseño de una unidad didáctica para el fortalecimiento de la comprensión lectora, de los estudiantes del grado tercero de la institución educativa Mariano Ospina de la Ciudad de Cúcuta. Bucaramanga: Universidad Autónoma de Bucaramanga.

ICFES. (2017, mayo 7). Colombia Aprende. \#SiempreDíaE. Recuperado de http://aprende.colombiaaprende.edu.co/ siemprediae/86438

Jolibert, J. (1991). Formar niños lectores/productores de textos propuesta de una problemática. Lectura y Vida, 3.

Lerner, D. (1986). Es posible leer en la escuela. Buenos Aires: Latino Americana de Lectura.

López, Y. (2013). El placer de la lectura y la escritura en la escuela. En Leer para comprender, escribir para transformar: palabras que abren nuevos caminos en la escuela. Bogotá: Ministerio de Educación Nacional.

Llamitas, M. E. (2013). Estrategias innovadoras en la comprensión lectora para el desarrollo de enseñanza aprendizaje de los niños de cuarto a séptimo año de educación básica del centro educativo Intercultural Bilingüe Humberto Vacas Gómez de la comunidad de Surupogios. Guaranda: Universidad Estatal de Bolívar.

Llanes, R. A. (2005). Comprensión lectora en los estudiantes de tercer grado de la escuela primaria. Monterey, México: Universidad Virtual tecnológica y de Estudios Superiores Monterey.

Márquez, C., \& Prat, A. (2005). Leer en clase de ciencias. España: Departamento de la Didáctica de las Matemáticas, de Lengua, de Ciencias Sociales de la Universidad Autónoma de Barcelona.

Ministerio de Educación Nacional. (2006). Estándares Básicos de claridad de Lengua castellana. Bogotá.

Ministerio de Educación Nacional. (2016). Derechos básicos del aprendizaje de lengua castellana. Bogotá: Colombia Aprende.

Ministerio de Educación Nacional. (2017). Índice sintético de calidad. Bogotá: ICFES.

Ministerio de Educación Nacional. (2017). Pruebas Saber $3^{\circ}, 5^{\circ}$ y $9^{\circ}$. Bogotá: ICFES.

Polya, G. (1965). Cómo plantear y resolver problemas. México: Trilla.

Proyecto Educativo Institucional. (2016). El camino hacia la excelencia. Los Patios, Norte de Santander: Institución educativa Colegio Integrado Fe y Alegría.

Rico, L., \& Lupiáñez, J. L. (2008). Competencias matemáticas desde una perspectiva curricular. España: Alianza Editorial.

Rodríguez, S. (2015). Relación entre las competencias de comprensión lectora y resolución de problemas matemáticos en los alumnos de tercero primaria de un establecimiento privado. Guatemala de la Asunción: Universidad Rafael Landívar.

Romero, E. A. (2012). Comprensión lectora y resolución de problemas matemáticos en los alumnos de segundo grado de primaria del Distrito Ventanilla, Callao. Lima, Perú: Universidad San Ignacio de Loyola.

Solé, I. (1987). Estrategias de lectura. Barcelona: Grao. 


\section{Relación de figuras}

Figura N¹. Estudiante de tercer grado, taller de "Tipología textual" la línea de tiempo.

Figura $N^{\circ} 3$. Estudiantes de tercero en la actividad de desarrollo de la intervención $N^{\circ} 4$ 88

Figura $N^{\circ} 5$. Actividad de desarrollo del taller la descripción.

Figura $N^{\circ} 6$. Elaboración del portafolio de talleres matemáticos por los estudiantes del grado 601 de la Institución Educativa Fe y Alegría del Municipio de Los Patios N. de S.

Figura $N^{\circ} 7$. Imagen con propuesta de un estudiante sobre los controles del ascensor del edificio como parte de la comprensión lectora.

Figura $N^{\circ} 8$. Planteamiento que hace el estudiante para resolver las situaciones. 91

Figura $N^{\circ} 9$. Actividad de inicio del taller No. 2, elaboración de glosario. 91

Figura $N^{\circ} 10$. Solución de situaciones en actividad de desarrollo y cierre del taller $N^{\circ} 2$ de los estudiantes de sexto grado. 92

Figura $N^{\circ} 11$. Taller 3. Conceptualización de la multiplicación partiendo de la suma. 92

Figura $N^{\circ} 12$. Interpretación de la ley de los signos en lenguaje cotidiano. 92

Figura N¹3. Ilustración del conflicto entre los positivos y negativos por un estudiante de 601. 93

Figura $N^{\circ} 14$. Actividad de coloreado con clave, aplicando la multiplicación de números enteros. 93

Figura $N^{\circ} 16$. Medición de temperatura corporal. 94

Figura $N^{\circ} 17$. Juego del plano cartesiano en el patio realizado por los estudiantes de 601, taller No. 5. 95

Figura $N^{\circ} 18$. Refuerzo de la actividad de desarrollo en el tablero por el docente. 95

Figura $N^{\circ} 19$. Parte de la evaluación individual del taller No. 5 95

Figura $N^{\circ} 21$. Representación del fraccionamiento de los alimentos. 96

Figura $N^{\circ} 22$. Solución gráfica en la actividad de cierre. 97

Figura $N^{\circ} 23$. Respuesta de un estudiante a una pregunta de nivel crítico. 97 